http://www.jfas.info

\title{
THERMODYNAMIC OPTIMIZATION OF HEAT EXCHANGER TANKS BY EXERGY ANALYSIS METHOD
}

\author{
M. Ghorbani ${ }^{1, *}$ and N. Hedayat ${ }^{2}$ \\ ${ }^{1}$ Department of Mechanical Engineering, Dezful Branch, Islamic Azad University, Dezful, \\ Iran \\ ${ }^{2}$ Faculty of technical and engineering, Dezful Branch, Islamic Azad University, Dezful, Iran
}

Published online: 15 May 2016

\begin{abstract}
The paper introduces heat exchanger tanks, detailing their dominant thermodynamic relations to obtain the exergy analysis relations of heat exchanger tanks. Heat exchanger tank is examined under various laboratory conditions, including the power of heat element inside the tank, mass flow rate of cooling water of tank wall and the mixer speed inside the tank which were all variable. The needed data relating to the water temperature inside the tank as output water after cooling the tank wall based on these conditions. The exergy loss (irreversibility) and efficiency diagrams were then drawn and the optimization parameters of performance and their range were evaluated using exergy analysis. This was meant to increase the efficiency and decrease the energy consumption. The results indicate that under thr circumstances of controlling mass flow rate of input cold water and power of heat element as well as the mixer speed, respectively, in their possible minimum and maximum measures, the system performs in optimal conditions according to exergy analysis.
\end{abstract}

Keywords: Thermodynamic optimization; heat exchanger tank; exergy analysis.

Author Correspondence, e-mail: milad_ghorbani1365@yahoo.com doi: http://dx.doi.org/10.4314/jfas.v8i3s.184 


\section{INTRODUCTION}

If a matter reaches its dead state (that is in thermal, mechanical and chemical balance with environment) from its initial state during a reversible process, the maximum accessible work is obtained which is called exergy or availability. The process of heat exchange between two fluids with different temperatures separated by a solid wall is found in many engineering applications. A heat exchanger conducts this process. Exchanger tank is one of the types that is highly used in oil and gas industry, petrochemical and power plants, coolers and heaters and also in food industry.

The thermodynamic methods for energy optimization that have been recently much considered as a powerful tool can be focused based on two criteria:

- A criterion that considers the exergy and its maximization as the performance evaluation criterion.

- A criterion that considers the entropy and its minimization as the performance evaluation criterion.

Both criteria have been referred in previous studies and various articles with some advantages, features and limitations, some of which are followed here:

- Hepbasli conducted a practical and general review of exergy analysis of thermodynamic machines as well as an estimation and evaluation of renewable energy in future. [1]

- In his three articles, Bejan discussed the analysis of the second law of thermodynamics in heat transfer and thermal design, generated entropy via heat transfer and fluid flow, and also the minimization of generated entropy. [2], [3], ,4]

- Gong et al. stated the economic and technical optimization of processes in environmental conditions by exergy. [5]

- Kakac et al. designed heat exchangers and determined their price. [6]

- Naphon evaluated the analysis of second law in the heat transfer of horizontal concentric tube heat exchanger. [7]

- Ozcelik optimized the shell and tube heat exchangers by genetic algorithm using exergy analysis. [8]

- Paniagua et al. offered a new simple method for estimation of exergy loss in heat 
exchangers. [9]

- Shukuya et al. published an introduction to the concept of exergy. [10]

- Yilmaz et al. examined the performance evaluation criteria of heat exchangers based on the analysis of second law. [11]

- In his study, Zhu combined the exergy analysis with pinch technology for processes. [12]

By examining the heat exchanger tank, the present study is aimed at thermodynamically optimize the heat transfer using exergy analysis. Optimization of every process decreases the energy loss and increases the efficiency. In contrast, lack of optimization increases both the costs and pollution rate. Therefore, it is expected that the thermodynamic optimization of heat exchanger tank and also finding the optimal range of each parameter would reduce the energy loss and costs and help the environmental health.

\section{FUNDAMENTAL RELATIONS AND CONCEPTS}

One of the most important concepts in thermodynamic studies is the concept of energy. Indeed, thermodynamics can be known as the science of energy. One of the most important thermodynamics relations is the mass conservation law or continuity equation:

$\left.\frac{d m}{\mathrm{dt}}\right)_{\mathrm{c} . \mathrm{v}}+\sum_{\mathrm{e}} \dot{\mathrm{m}}_{\mathrm{e}}-\sum_{\mathrm{i}} \dot{\mathrm{m}}_{\mathrm{i}}=0$

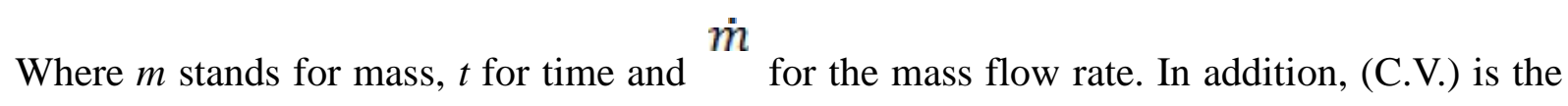
control volume, (c.s.) the control surface, (out) or (e) the output and (in) or (i) represent the input in the whole article.

\subsection{The first and second laws of thermodynamics}

The first law of thermodynamics, also known as the energy conservation law, is fundamental for the relations between energy interactions and its various forms. Based on the experiments, the first law of thermodynamics states that energy cannot be created or destroyed but only can be transformed from one form to another. This law cannot be mathematically proved; however, no natural process or phenomenon has violated the first law of thermodynamics. The first law for the control volume is as follows: 


$$
\left.\dot{Q}-\dot{W}=\frac{\partial U}{\partial t}\right)_{c . v}+\sum_{\theta} \dot{m}_{\theta}\left(h+\frac{v^{2}}{2}+g z\right)-\sum_{i} \dot{m}_{i}\left(h+\frac{v^{2}}{2}+g z\right)
$$

Where ${ }_{\text {Q }}^{\dot{Q}}$ stands for the heat transfer rate, ${ }^{\dot{W}}$ for the performed work rate, $U$ for the internal

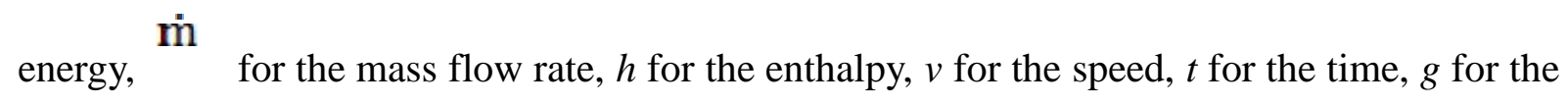
gravity acceleration and $z$ for the height.

Maintaining the quality of energy is of great importance for scientists and engineers alike. The second law of thermodynamics is a good measure for determining the quality and loss rate of energy during the processes. The second law of thermodynamics is founded upon the experimental observations. There are two classical expressions for the second law known as the Kelvin - Planck and Clausius which are both equivalent of one another. The second law as the principle of entropy increase for the control volume is stated as follows:

$$
\left.\frac{d S}{\mathrm{dt}}\right)_{\mathrm{c} . \mathrm{V}}+\sum_{\mathrm{e}} \dot{\mathrm{I}}_{\mathrm{e}} S_{e}-\sum_{\mathrm{i}} \dot{\mathrm{H}}_{\mathrm{i}} S_{i}=\sum_{c s} \frac{Q}{T}+\dot{S}_{g e n}
$$

Where, $S$ stands for the entropy, $\dot{\mathbf{m}}$ for the mass flow rate, $\dot{\mathbf{Q}}$ for the heat transfer rate, $T$ for temperature and $\dot{S}_{g e n}$ for the rate of generated entropy.

\subsection{Heat exchangers}

Heat exchangers are the sort of devices that generally provide the flow of thermal energy between two or more fluids under different temperature conditions. They are applied in various domains including, electricity generation sector, environmental engineering, unused heat recovery, air conditioning, and refrigeration, oil and petrochemical industry, astronomy and food industries. There are two approaches for analyzing heat exchangers: the Logarithmic Mean Temperature Difference (LMTD) method for design problems (determining the surface of heat exchange) and the Effectiveness-Number of Transfer Units $(\varepsilon-$ NTU) method for analytical problems (finding the fluid's output temperatures). This paper primarily classifies the heat exchangers and subsequently the heat exchanger tank as follows:

- Classification based on the type and the temperature of the fluid and its contact: heat 
transfer and recovery types; direct and indirect contact.

- Classification based on the exchanger's mechanical construction and their structure: double-tube, shell and tube and spiral tube heat exchangers; gasket and spiral plate and lamella heat exchangers; fin heat exchangers including fin-plate and tube-plate heat exchangers.

- Classification based on the flow direction of hot and cold fluid: co-current (flow), counter-current and cross-current heat exchangers.

- Classification based on the mechanism of heat transfer between the cold and hot fluid: single phase convection on both sides; single phase convection on one side, two phase convection on the other side; and finally, two-phase convection on both sides.

\subsection{Heat exchanger tank}

Heat exchanger tank, similar to a simple reactor, has an insulated cylindrical tank with water input and output, in which there exist water pipes, heat element and a mixer. Along with increasing the temperature of tank's water by the heater, the tank's wall can be cooled by its surrounding spiral pipes, the input water mass flow rate of which is adjustable. The input and output temperature of water for cooling is displayed. The power of heat element and the mixer speed are alterable for regulating the temperature of tank's water and uniforming the water, respectively. Nevertheless, the temperature of heater and tank's water is displayed on the exchanger.

\subsection{Exergy}

The first law of thermodynamics only assesses different energies quantitatively. According to this law, $100 \mathrm{kj}$ heat is equal to $100 \mathrm{kj}$ work. While, in practice, the total heat energy is not converted to work. The first law of thermodynamics does not involve any restriction regarding the direction of work or heat pass. These shortages were removed by the introduction of the second law of thermodynamics which is able to predict the advance route of reactions, processes and even the rate of cycle losses. The direct usage of first and second law of thermodynamics resulted in exergy analysis that is considered to be a strong and useful device in qualitative and quantitative evaluation of existing energies. By merging the first and second laws of thermodynamics, the exergy analysis makes possible the determination of 
desired method of Energy Systems Analysis as well as a clear recognition of energy levels and undesirable thermodynamic processes of a system.

Exergy or availability is defined as the maximum power of a system or control volume to carry out a work until it reaches the dead state. A dead state is a state in which the system or control volume would be in complete balance (including temperature, pressure, mechanical, chemical and etc.) with the environment or be without any potential difference to environment.

\subsection{Different forms of exergy}

Like different forms of energy including kinetic, potential, physical, and chemical, etc., which form the total energy of one system, a system's exergy (availability) also denotes the total exergy of different forms of energy within. Accordingly, the exergy of each system in a specific state is only determined by summing the exergy of each existing forms of energy within that system.

$$
\begin{gathered}
E X \underset{E}{E} X_{\text {kinetic }}+E X_{\text {potential }}+E X_{\text {physical }}+\dot{E} X_{\text {heat }}+ \\
E X_{\text {diffusion }}+E X_{\text {chemical }}
\end{gathered}
$$

$E X$ is the rate of total exergy.

\section{- Kinetic exergy}

Kinetic energy is a form of regular mechanical energy which can be totally converted to work. Therefore, the exergy of kinetic energy of one system equals the kinetic energy itself. This is not related to the environment's temperature and pressure.

$$
E X_{\text {kinetic }}=\frac{1}{2} \dot{m} V^{2}
$$

$$
\text { Where } \dot{m} \text { and } V \text { respectively denote the mass flow rate and speed. }
$$

\section{- Potential exergy}

Potential exergy is also a form of regular mechanical energy which can be totally converted to 
work. Therefore, the exergy of potential energy of one system equals the potential energy itself. This is not related to the environment's temperature and pressure.

$\dot{E} X_{\text {potential }}=\dot{m} g z$

(6)Where

$\dot{m}$

denotes the mass flow rate, $g$ the gravity acceleration and $z$ the height.

\section{- Physical exergy}

Physical exergy is the maximum power of a system or control volume to do a work until it reaches the dead state. For the steady state - steady flow conditions and regardless of potential and kinetic energy, we have:

$\dot{E} X_{\text {physical }}=\dot{m}\left[\left(h-h_{0}\right)-T_{0}\left(s-s_{0}\right)\right]$

Where, $\stackrel{\dot{\mathrm{m}}}{ }$ represents the mass flow rate, $h$ for the enthalpy, $S$ for the entropy, $\mathrm{T}_{0}$ for the environment temperature and zero index for the dead state.

\section{- Heat transfer exergy}

Heat transfer exergy from the control surface equals the maximum obtainable work from the transferred heat energy. In this case, the environment is considered as the source of heat energy with zero potential. Thus, the exergy of system or control volume's heat transfer is obtained from the following equation:

$E X_{\text {heat }}=\dot{Q}_{s}\left(1-\frac{T_{0}}{T_{S}}\right)$

Where $\dot{Q}_{s}$ stands for the heat transfer rate of system or control volume, $T_{s}$ for the temperature of control surface and $T_{0}$ for the environment temperature.

\section{- Diffusion exergy}

Diffusion exergy equals the maximum obtainable work which is yielded because of the change of a system from partial (limited) to complete dead state and reaches the complete 
balance with the environment in that system. This process includes the heat transfer and mass exchange between the system and environment: ${ }^{E} X_{\text {dif fusion }}$

\section{- Chemical exergy}

Chemical exergy is an accessible amount of work done by a matter that is generated in the environment conditions when the matter chemically interacts with the components of environment and the interaction's products ultimately reach a dead state: $\quad E^{\prime} X_{\text {chemical }}$

\subsection{Exergy transfer methods}

Exergy can be transferred in three ways: heat and mass transfer and work. In heat and work transfer, the exergy is increased and decreased respectively. In addition, it increases for the input mass and decreases for the output mass transfer:

- Exergy transfer via heat transfer:

$$
E X_{\text {heat }}=\dot{Q}_{S}\left(1-\frac{T_{0}}{T_{S}}\right)
$$

- Exergy transfer via mass transfer; regardless of potential and kinetic energy we have:

$$
\dot{E} X_{\text {physical }}=\dot{m}\left[\left(h-h_{0}\right)-T_{0}\left(s-s_{0}\right)\right]
$$

- Exergy transfer via work; considering the fact that exergy is conversion ability to useful work, we have:

For other types of work including the axial and electrical work, it is equal to the work of itself. Meaning:

$$
E X_{\text {work }}=\dot{W}
$$

In case there is a border work $\vec{W}_{f}$, the exergy will be the different of the work and border work:

$$
E X_{\text {work }}=\dot{W}-\dot{W}_{f}
$$


Considering the atmosphere pressure ${ }^{P_{0}}$, the initial volume ${ }^{V_{0}}$, and the final volume $V$, and the border work of the system equals:

$$
\dot{W}_{f}=P_{0}\left(V-V_{0}\right)
$$

\section{THE EXERGY ANALYSIS OF EXCHANGER TANK}

By using the thermodynamic relations of mass conservation (continuity equation), energy conservation (the first law), entropy balance (the second law) and exergy balance, it will be concluded that the irreversibility rate or the rate of exergy destroyed in an exchanger tank equals the multiplication of environment's temperature and the rate of generated entropy:

$$
\begin{aligned}
\sum \dot{E} X_{\text {destroyed }}= & \sum \dot{E} X_{\text {in }}-\sum \dot{E} X_{\text {out }}=\sum \dot{E} X_{\text {heat }}-\sum \dot{E} X_{\text {work }}+ \\
& \sum \dot{E} X_{\text {mass }, \text { in }}-\sum E X_{\text {mass }, \text { out }}
\end{aligned}
$$

Where ${ }^{E X_{\text {destroyed }}}$ stands for the rate of exergy destroyed, and $E X_{\text {output }}$ and $E \dot{E}$ input are respectively the rate of output and input exergies.

The rate of heat exergy:

$\sum E X_{\text {heat }}=\dot{Q}_{\text {loss }}\left(1-\frac{T_{0}}{T}\right)$

The rate of work exergy:

$\sum E X_{\text {work }}=\dot{W}_{\text {element }}+\dot{W}_{\text {mixer }}$

The rate of input mass exergy:

$\sum E X_{\text {mass } i n}=E X_{H z o, i n}=\dot{m}_{i n} \psi_{i n}=\dot{m}_{i n}\left[\left(h_{i n}-h_{0}\right)-T_{0}\left(s_{i n}-s_{0}\right)\right]$ 
The rate of output mass exergy:

$\sum E X_{\text {mass out }}=E X_{H 20,0 u t}=\dot{m}_{\text {out }} \psi_{\text {out }}=\dot{m}_{\text {out }}\left[\left(h_{\text {out }}-h_{0}\right)-T_{0}\left(s_{\text {out }}-s_{0}\right)\right]$

From the second law, we have the rate of generated entropy:

$\dot{S}_{g e n}=\sum_{\mathrm{e}} \dot{\mathrm{I}}_{\text {out }} S_{\text {out }}-\sum_{\mathrm{i}} \dot{\mathrm{I}}_{\text {in }} S_{\text {in }}-\sum \frac{\mathrm{Q}_{\mathrm{K}}}{\mathrm{T}_{\mathrm{k}}}$

Placement of the relations yields the following equation ( $k$ index in the above relation represents the place of heat transfer). It should be noted that since the rate of heat loss exceeds

our control volume, a negative sign is multiplied to it in the final equation and $\dot{Q}_{\text {loss }}$ is obtained by a positive sign as follows:

$\dot{I} \quad=\quad \dot{E} X_{\text {destroyed }}=T_{0} \dot{S}_{\text {gen }}=T_{0}\left[\dot{m} s_{\text {out }}-\dot{m} s_{\text {in }}-\frac{Q_{\text {loss }}}{T}\right]$

$\dot{Q}_{\text {loss }}=\dot{W}_{\text {element }}+\dot{W}_{\text {mixer }}$

$+\dot{m}\left(h_{\text {out }}-h_{\text {in }}\right)$

Where ${ }^{\dot{I}}$ stands for the irreversibility rate, ${ }^{\dot{E} X_{\text {destroyed }}}$ for the rate of exergy loss or destroyed, ${ }^{\mathbf{T}_{0}}$ for the environment's temperature, ${ }^{\dot{S}_{g e n}}$ for the rate of generated entropy, $\dot{m}$ for the mass flow rate, $h$ for the enthalpy, $S$ for the entropy, $T$ for the water temperature of tank exchanger, $\dot{W}_{\text {element }}$ for the power of heat element (heater), $\dot{W}_{\text {mixer }}$ for the mixer 
power and $\dot{Q}_{\text {loss }}$ for the rate of heat transfer loss from the control surface or the tank exchanger's wall.

\subsection{The exergy efficiency and its improvement potential}

The exergy efficiency $\varepsilon$ or the second law's efficiency is defined as the ratio of output exergy $\dot{E} X_{\text {output }}$ to the rate of input exergy $\dot{E} X_{\text {input }}$ and $\dot{E X}_{\text {destroyed }}$ is the rate of exergy destroyed:

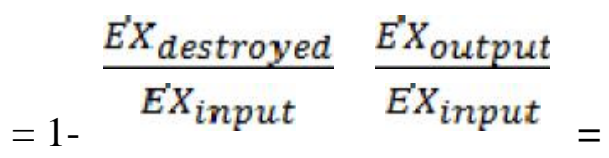

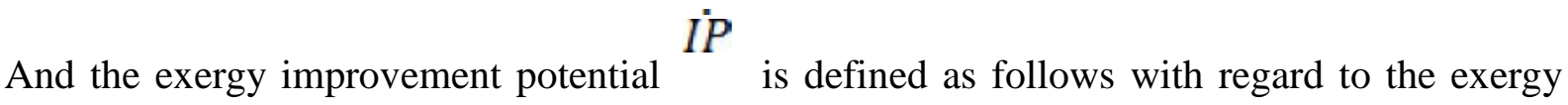
efficiency $\varepsilon$ :

$$
\stackrel{I P}{=}(1-\varepsilon)\left(E X_{\text {in }}-E X_{\text {out }}\right)
$$

\section{DISCUSSION AND ANALYSIS ON THE DIAGRAM}

By examining the heat exchanger tank in laboratory and considering three parameters of mixer speed, power of heat element and the cold water's mass flow rate (for cooling the tank's wall) as the change parameters and registration tank's water temperature and the output cooling water, the exergy loss and efficiency (per minute in a 5 min period) was calculated and shown on the diagram. The following issues should be considered, however:

- Temperature of the input water and environment is considered to be 298 kelvin.

- The amounts of enthalpy and entropy are read from the table of water saturation for saturated liquid.

- The water's output temperature, power of heat element and the input cold water's mass flow are displayed on the exchanger. The power of mixer is obtained by multiplication of the torque and the mixer's angular velocity which is specified on the exchanger (thus, the 
mixer power and speed are directly related)

- The rate of exergy destroyed and its efficiency are respectively obtained through Eq. (20) and (22).

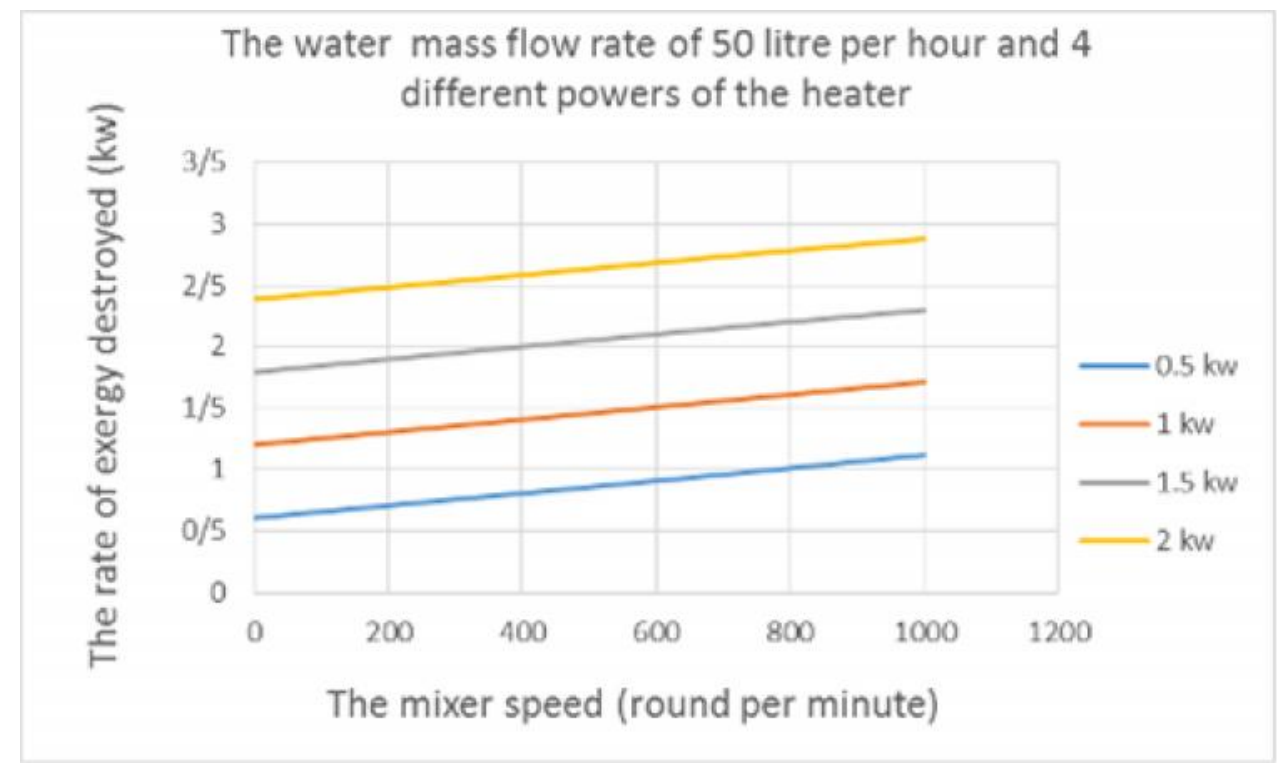

Diagram 1. The rate of exergy destroyed according to the mixer speed for a water mass flow rate of 50 litres per hour

Diagram 1 shows the rate of exergy destroyed according to the mixer speed for the water mass flow rate of 50 litres per hour. Results indicate that along with the increase of mixer speed (during 0-1000 round per minute) and the heater power in four different values $(0.5,1$, $1.5 \& 2$ ) kilo watt ( $\mathrm{kw})$, the exergy loss or destroyed availability or irreversibilities have been linearly increased. It is thus concluded that the less the heater power and mixer speed, the less the exergy losses. 


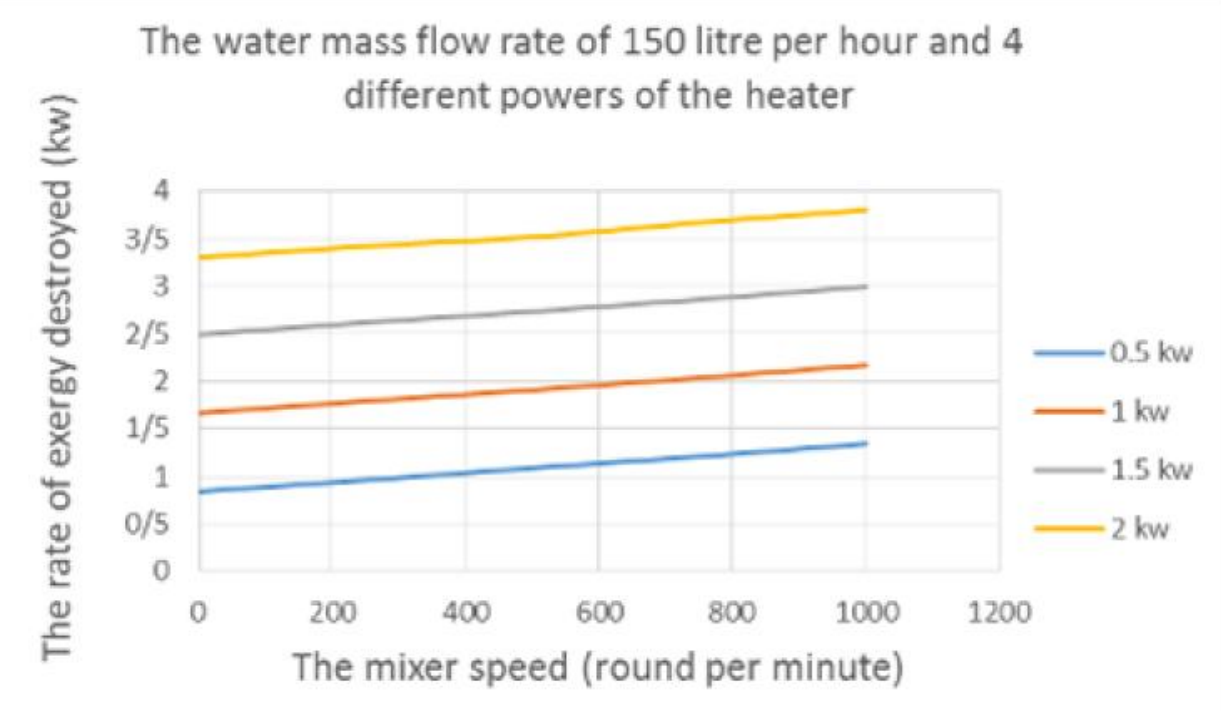

Diagram 2. The rate of exergy destroyed according to the mixer speed for a water mass flow rate of 150 litres per hour

Diagram 2 shows the rate of exergy destroyed according to the mixer speed for the water mass flow rate of 150 litres per hour. Results indicate that along with the increase of mixer speed (during 0-1000 round per minute) and the heater power in four different values $(0.5,1$, $1.5 \& 2$ ) kilo watt (kw), the exergy loss) or destroyed availability or irreversibilities have been linearly increased. It is thus concluded that the less the heater power and mixer speed, the less the exergy losses.

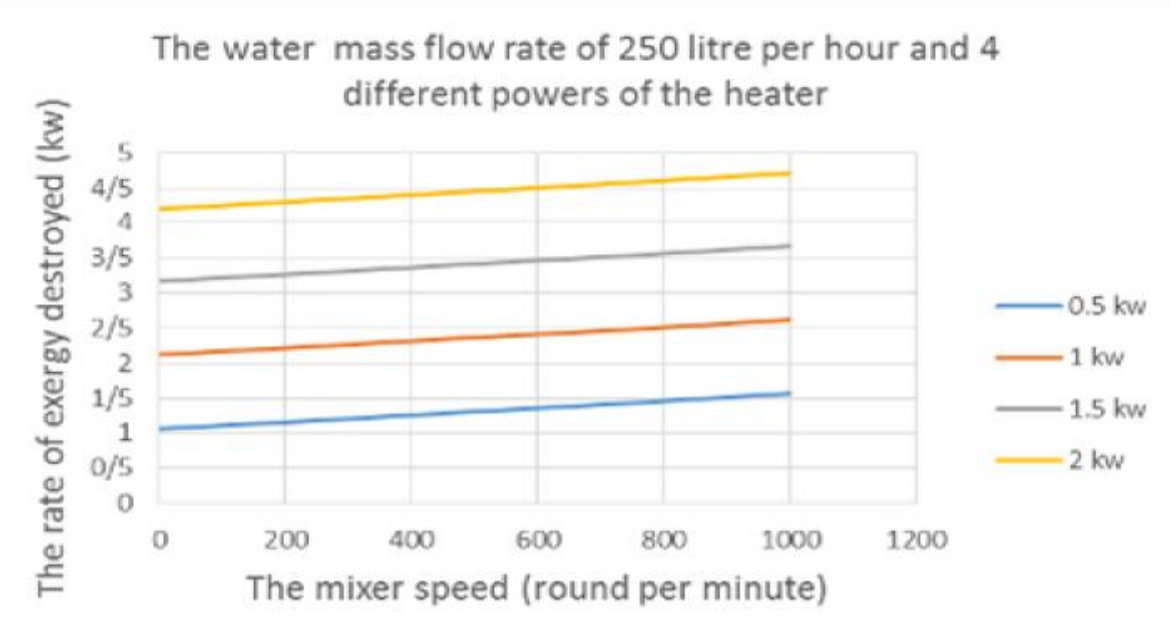

Diagram 3. The rate of exergy destroyed according to the mixer speed for a water mass flow rate of 250 litres per hour 
Diagram 3 shows the rate of exergy destroyed according to the mixer speed for the water mass flow rate of 250 liter per hour. Results indicate that along with the increase of mixer speed (during 0-1000 round per minute) and the heater power in four different values $(0.5,1$, $1.5 \& 2)$ kilo watt $(\mathrm{kW})$, the exergy loss or destroyed availability or irreversibility have been linearly increased. From the findings and also by comparison of exergy values in in diagrams (1), (2), \& (3), it can be concluded that the less the heater power, mixer speed as well as the cold water mass flow rate, the less the exergy losses.

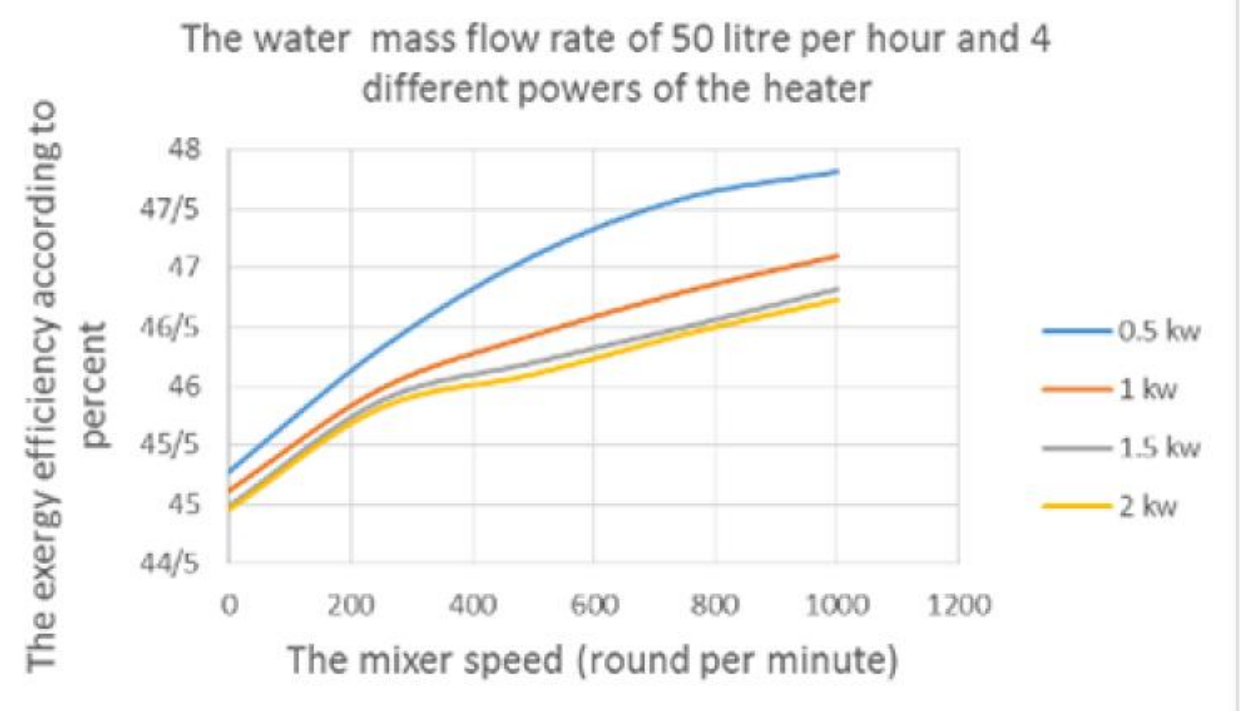

Diagram 4. The rate of exergy efficiency according to the mixer speed for a water mass flow rate of 50 litres per hour

Diagram 4 shows the rate of exergy efficiency according to the mixer speed for the water mass flow rate of 50 liter per hour. Results indicate that along with the increase of mixer speed (during 0-1000 round per minute) and decrease of heater power in four different values $(0.5,1,1.5 \& 2)$ kilo watt $(\mathrm{kW})$, the exergy efficiency has been linearly increased. It is thus concluded that the less the heater power and the more the mixer speed, the more the exergy efficiency. 


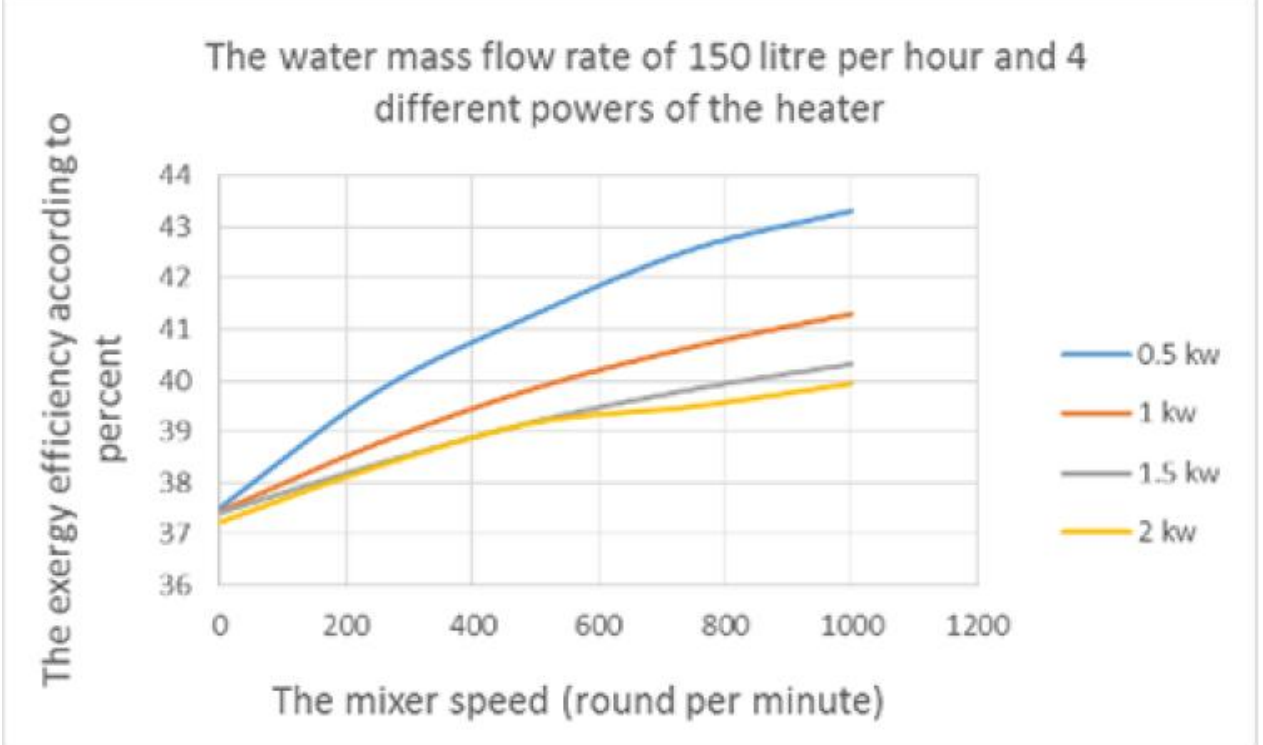

Diagram 5. The rate of exergy destroyed according to the mixer speed for a water mass flow rate of 150 litres per hour

Diagram 5 shows the rate of exergy efficiency according to the mixer speed for the water mass flow rate of 150 liters per hour. Results indicate that along with the increase of mixer speed (during 0-1000 round per minute) and decrease of heater power in four different values $(0.5,1,1.5 \& 2)$ kilo watt $(\mathrm{kW})$, the exergy efficiency has been linearly increased. It is thus concluded that the less the heater power and the more the mixer speed, the more the exergy efficiency.

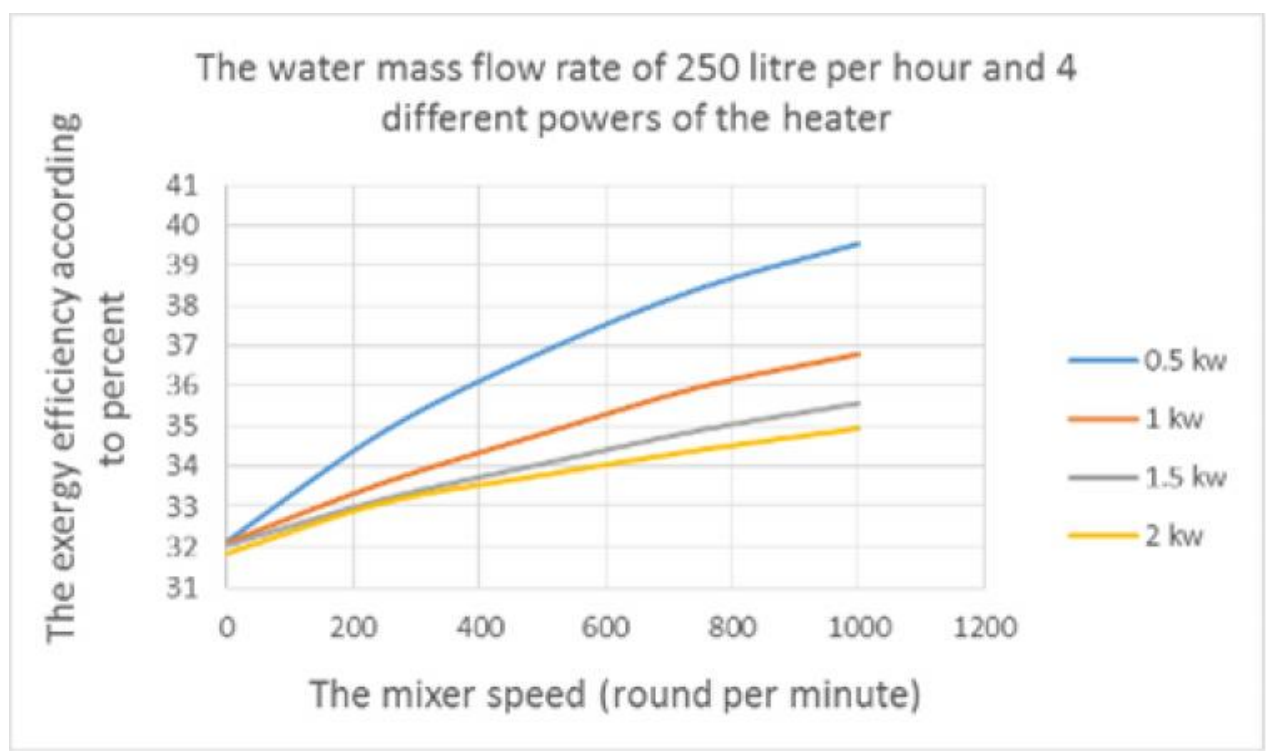

Diagram 6. The rate of exergy destroyed according to the mixer speed for a water mass flow rate of 250 litres per hour 
Diagram 6 shows the rate of exergy efficiency according to the mixer speed for the water mass flow rate of 250 liters per hour. Results indicate that along with the increase of mixer speed (during 0-1000 round per minute) and decrease of heater power in four different values $(0.5,1,1.5 \& 2)$ kilo watt $(\mathrm{kW})$, the exergy efficiency has been linearly increased. From the findings and also by comparing the values of exergy efficiency in diagrams (4), (5), \& (6), it can be concluded that the less the heater power and the cold water mass flow rate and the more the mixer speed, the more the exergy efficiency.

\section{RESULTS}

Considering the diagrams and aforementioned relations, it is concluded that:

- The rate of exergy destroyed increased along with the increasing of each of three parameters (the input cool water mass flow rate, power of heat element and mixer power or speed). However, this was predictable from the analytical relations and has also been confirmed by the experimental results and diagrams.

- Based on the analytical relations, the exergy efficiency increases along with decrease in each of the three parameters (the input cool water mass flow rate, power of heat element and mixer power or speed). Except for the mixer speed, it has been confirmed by the experimental results and diagrams (this sentence is incomplete and not meaningful). The results and diagrams indicate that the increase in the mixer speed has a corresponding increase in the exergy efficiency that is not predictable from the analytical relations. The main reason for this difference lies in the fact that with the increase of mixer speed and thus, mixture of the water inside the heat exchanger tank, the coefficient of heat transfer convection of the tank is increased. This helps the system to reach a homogeneous and uniform condition faster that leads to higher efficiency, as the experimental results and diagrams confirm.

- Therefore, for the optimal performance of a heat exchanger, the result of which is an increase in the system's efficiency and productivity, a decrease in the energy consumption and system's loss. Finally environmental pollution, it is economic to control the input cold water mass flow rate and heat element power in their possible minimum level and also to 
control the mixer power (mixer speed) in its possible maximum level.

- According to the values of exergy efficiency shown in diagrams, the optimized range for the cold water mass flow rate was 50-150 litres per hour, for the heater power was $0.5-1 \mathrm{~kW}$ and for the mixer power was 750-1000 rpm. The efficiency has been its highest level in these ranges; meaning that the system has been performing in optimized conditions according to exergy analysis.

\section{REFERENCES}

[1] Arif Hepbasli,2006, A key review on exergetic analysis and assessment of renewable energy resources for a sustainable future, Department of Mechanical Engineering, Faculty of Engineering, Ege University, TR-35100 Bornova, Izmir, Turkey.

[2] Bejan, A., 1982, "Second-law analysis in heat transfer and thermal design", Adv. Heat Transfer", No. 15.

[3] Bejan, A., 1982, "Entropy Generation through Heat and Fluid Flow", wiley, New York.

[4] Bejan, A., 1995, "Entropy Generation Minimization", CRC Press, New York.

[5] Gong, M. And wall, g., 1997, "on exergetics economics and optimization of technical processes to meet environmental conditions", Chinese and American society engineers.

[6] Kakac, S. and Liu, H., 1997, "Heat Exchangers Selection Rating, and Thermal Design, CRC Press", New York.

[7] Naphon, P., 2006, "second law analysis on the heat transfer of the horizontal concentric tube heat exchangers," Thailand.

[8] Ozcelik, Y., 2007, "exergetic optimization of shell and tube heat exchangers using a genetic basedalgorithm, Ege university", Turkey.

[9] Paniagua, I. and Martin, J., 2013, "A new simple method for estimating exergy destruction in heat exchangers", university politecnica de Madrid.

[10] Shukuya, M., and Hammeche, a., 2002, "introduction of the concept of exergy" , Yokohama .

[11] Yilmaz, M., Sara, O. and Karsli, S., 2001, "performance evaluation criteria for heat exchangers based on second law analysis", Ataturk university, Turkey. 
[12]Zhu. X. Feng.X., 1997, Combined Pinch and Exergy Analysis for Process Modification, Applied Thermal Engineering, vol 17, pp 249-261.

\section{How to cite this article:}

Ghorbani $\mathrm{M}$ and Hedayat $\mathrm{N}$. Thermodynamic optimization of heat exchanger tanks by exergy analysis method. J. Fundam. Appl. Sci., 2016, 8(3S), 314-331. 